\title{
Utilização dos laboratórios de informática em escolas municipais de Passo Fundo/RS ${ }^{1}$ Use of Computer Labs in Schools of Passo Fundo/RS
}

\author{
Karina Marcon ${ }^{2}$ \\ Adriano Canabarro Teixeira ${ }^{3}$
}

\begin{abstract}
This paper is a report on the experience achieved in a research that has been accomplished in ten schools of the teaching municipal network of Passo Fundo/RS. The purpose of that research was to verify, in the educative process dynamics, which were the reflections on the network technology usage by teachers and students. Before the actual research could be carried out, there was the accomplishment of a teaching training project which aimed on supplying teachers with theoretical and practical subjects of digital inclusion. After the conclusion of the project, a field research was needed with the purpose of verifying the right functioning of the computer labs, as well as analyzing if the main goal of the project was achieved and if the network technology usage in teaching, learning and in digital inclusion were, in fact, taking place as a dynamic process.
\end{abstract}

Resumo. Este artigo traz a experiência de uma pesquisa realizada em dez escolas da Rede Municipal de Ensino de Passo Fundo/RS, cujo objetivo foi verificar na prática pedagógica a apropriação das tecnologias de rede por professores e alunos após a realização de um projeto de formação docente, no qual o fundamento principal foi oferecer subsídios teóricos e práticos de inclusão digital aos professores participantes. Após a execução do projeto, pareceu pertinente realizar uma pesquisa com o intuito de averiguar a forma de funcionamento dos laboratórios de informática, bem como de analisar se os princípios idealizados pelo projeto foram atendidos e se efetivamente estava ocorrendo um processo horizontal, dinâmico e autônomo de apropriação das tecnologias e de inclusão digital.

\section{Proposta de pesquisa: conhecendo o campo de estudo}

A proposta da inicial da pesquisa foi visitar - de março a maio de 2008 - dez escolas municipais que participaram de um Projeto de Formação Docente realizado em final de 2006 e início de 2007, com a intenção de analisar as mudanças ocorridas na prática escolar após a execução do mesmo. O projeto intitulado Formação Docente como exercício inclusivo de autoria colaborativa, foi composto por cinco módulos, com vistas a fomentar uma

\footnotetext{
${ }^{1}$ Este artigo é um fragmento da dissertação de Mestrado realizada pela aluna Karina Marcon, com a orientação do professor. Dr. Adriano Canabarro Teixeira.

${ }^{2}$ Mestre em Educação pela Universidade de Passo Fundo (UPF) - Brasil. E-mail: kamarcon@ gmail.com

${ }^{3}$ Professor do Curso de Ciência da Computação e do Mestrado em Educação - Universidade de Passo Fundo (UPF). E-mail: teixeira@upf.br

V. $7 \mathrm{~N}^{\mathrm{o}}$ 3, dezembro, 2009
} 
apropriação criativa das tecnologias. Os módulos previam, além da utilização do Kelix ${ }^{4}$, das ferramentas da internet e do Pacote BrOffice, a Construção de Projetos de Aprendizagem que pudessem explorar as possibilidades que um laboratório de informática pode propiciar na escola.

Em virtude de imprevistos oriundos de problemas técnicos ou pela falta de sujeitos capacitados em assumir a responsabilidade pelos laboratórios, a visita não pôde ser realizada em três escolas.

Na primeira, o servidor de acesso à internet estava com problemas, "impossibilitando", segundo os dirigentes da escola, o uso do laboratório. Essa questão remete ao que Lemos (2003) menciona na terceira lei da cibercultura, a transformação do PC em CC - Personal Computer em Computador Conectado. Na dinâmica social atual, um computador sem acesso à internet perde sua função, ou seja, não serve, não atende mais às demandas existentes. Sem acesso à internet, o que fazer? Algumas funções básicas de utilização do computador poderiam, mesmo assim, ser exploradas, como o treinamento em editores de texto, planilhas eletrônicas, habilidades com desenhos ou mesmo alguns jogos. Entretanto, o grande referencial de um computador atualmente é o acesso ao mundo através da internet como um meio de comunicação em que são liberados os pólos de emissão (LEMOS, 2003), e também para o acesso a diversas fontes de conhecimento. Porém, nessa situação ainda há que se questionar essa não-utilização do laboratório na escola, fato que pode ser apontado como uma inabilidade ou como reflexo de uma visão parcial da informática educativa, uma vez que, estar sem internet, não impossibilita o uso do laboratório, pois outros recursos ainda poderiam ser utilizados, como, por exemplo, os softwares educacionais do Kelix.

Na segunda escola o empecilho aconteceu porque o grupo do Kelix/UPF testou uma versão atualizada do programa com outra distribuição, mas que até então não estava funcionando adequadamente. Como medida para solucionar esse problema, o próprio grupo, até final de maio de 2008, estava testando novas alternativas, tendo até mesmo recolhido algumas máquinas para fazer experimentos na própria universidade.

$\mathrm{Na}$ terceira escola a visita também não pôde ser realizada porque foi mencionado que a professora que participou do curso de Formação Docente teria saído da escola, motivo pelo qual as séries do Ensino Fundamental não estavam até então utilizando o laboratório: falta de uma pessoa capacitada para conduzir o trabalho. Percebem-se três fatores importantes nessa situação: o primeiro diz respeito à necessidade de que mais de uma pessoa faça o curso de formação docente, para que possa, na falta da outra, suprir a demanda existente. O segundo fator diz respeito à questão da dinâmica do uso do laboratório: quando está centralizado em uma só pessoa, o laboratório deixa de exercer suas funções na medida em essa pessoa é impossibilitada, seja pela saída da escola, por motivo de doença, ou por qualquer eventual contratempo. O terceiro diz respeito à carência de momentos de formação específica nas licenciaturas, situação que contribui para que os professores não desenvolvam habilidades técnico-pedagógicas de apropriação dessas tecnologias.

Esses três fatores remetem à necessidade de se pensar na utilização do laboratório sob o viés de uma cultura de rede (CASTELLS, 2005; CAPRA, 2002). De acordo com Capra (2002, p.93) o padrão em rede - network pattern - é um dos padrões de organização mais

\footnotetext{
4 Solução tecnológica livre implementada nas escolas. Mais informações em: <http://kelix.upf.br>.
}

V. $7 \mathrm{~N}^{\mathrm{o}}$ 3, dezembro, 2009 
básicos de todos os sistemas vivos. Em todos os níveis de vida - desde as redes metabólicas das células até as teias alimentares dos ecossistemas - os componentes e os processos dos sistemas vivos se interligam em forma de rede.

Diante dessa compreensão sistêmica da vida, a sociedade passou a ser analisada sob esse viés das redes principalmente a partir dos estudos do sociólogo Castells (2005). Capra explica que as redes sociais são, antes de mais nada, "[...] redes de comunicação que envolvem a linguagem simbólica, os limites culturais, as relações de poder e assim por diante" (2002, p. 94).

Neste sentido, precisa-se idealizar uma cultura de rede na apropriação das tecnologias e, também, na dinâmica de utilização dos laboratórios, buscando com que as ações sejam descentralizadas para que mais pessoas tenham autonomia de levar o projeto adiante quando, por motivos de força maior, este viesse a ser interrompido.

Claro que, ao se pensar na formação de mais docentes, está implícita a questão dos custos, elemento que, muitas vezes, impede a realização de muitos serviços públicos. Entretanto, como alternativa, é preciso que se pense a questão da multiplicação dos saberes, ou seja, o professor que participou do projeto dividindo seus conhecimentos com os demais.

Quanto a isso, surgem algumas questões: os demais professores querem tomar conhecimento desses saberes? Será que o medo, a angústia e os desafios - barreiras existentes para os professores trabalharem em um laboratório de informática - são maiores do que o conhecimento que eles mesmos têm sobre informática educativa e suas contribuições para os processos educativos? Não valeria a pena arriscar, tentar? Como ficam os alunos e seus desejos de ter uma aula usando o computador?

Frente a essas justificativas apresentadas, em função do cronograma previsto para a investigação, a pesquisadora não entrou mais em contato com essas três escolas depois da primeira semana de maio, considerando, assim, canceladas as visitas pelos motivos mencionados. Nas outras 07 escolas a pesquisadora pôde, enfim, conhecer a realidade. Percebeu-se que os professores, muitas vezes, possuíam desejos semelhantes quanto à realização de processos de inclusão digital, mas as ações, geralmente, eram um pouco diferentes.

\section{Formação dos participantes vinculados diretamente ao laboratório de informática}

Quando se pensa em trabalhar diretamente com computadores nas escolas, muitas vezes a primeira reflexão se volta para o domínio que é preciso ter sobre a máquina. Nas sete escolas visitadas, dos professores entrevistados, apenas um não tinha participado do curso de Formação Docente proposto, mesmo assim, assumiu as aulas no laboratório. Dos outros seis professores que participaram do projeto, todos trabalham no laboratório desde que o mesmo abriu, ou seja, há um ou dois anos, com exceção de uma escola, na qual o laboratório só começou a funcionar em março de 2008.

Os professores entrevistados eram de diferentes áreas de formação: três em Pedagogia Séries Iniciais, dois em Ciências Biológicas, sendo que um desses ainda tinha formação em Ciências Contábeis e Matemática; um em Química e outro em Geografia. Três com especialização: um em Educação Matemática; outro em Supervisão Escolar e Filosofia e outro em Gestão e Organização Escolar. Um professor também possuía o título de Mestre em 
Educação. As diferentes áreas envolvidas demonstram que não cabe mais o discurso comum no qual a formação em determinada área é empecilho para trabalhar com informática educativa.

Das sete escolas visitadas, apenas três tinham monitores. Um cursando Ciência da Computação, que atendia duas escolas, e o outro Educação Física. É importante ressaltar que no início do projeto todas as escolas contavam com o suporte técnico de um monitor, o que facilitava na resolução de algumas questões vinculadas especificamente ao manuseio das máquinas e dos programas. No entanto, por questões de ajustes internos da Prefeitura Municipal de Passo Fundo, a monitoria foi descontinuada no final de 2007, prejudicando assim o andamento do projeto.

\section{Dinâmica de uso do laboratório}

REGRAS DE CONVÍVIO NO LABORATÓRIO DE INFORMÁTICA:

Cultivar a amizade. Sorrir. Atenção. Trocar e esperar a sua vez. Ser solidário. Silêncio. Paciência. Ouvir. Ter cuidado com a máquina. Respeitar a orientação da professora. O uso do computador é mais uma ferramenta para o nosso aprendizado. Vamos aproveitar o máximo.

Boa aula, Equipe Diretiva.

No laboratório de informática de uma escola visitada existiam várias folhas espalhadas pelas paredes ou afixadas ao lado dos computadores, com os dizeres acima transcritos. Acredita-se que inclusão digital também é isso, promover características essenciais dos seres humanos. Por isso, considera-se essas regras bem acolhedoras, porque observam, acima de tudo, a importância das relações humanas.

Ao apresentar a dinâmica de funcionamento dos laboratórios visitados, pretende-se demonstrar como os mesmos vêm funcionando a partir do depoimento dos monitores, professores e gestores, sobre os procedimentos antes do uso e também sobre a distribuição de horários.

Foi questionado aos monitores se eles identificavam diferenças entre os professores que participaram dos módulos de formação na UPF e os que não participaram. Ambas as respostas apontaram que existem diferenças: "Sim, percebo. Até auxiliar, assim, o aluno, que para alguns os alunos pedem ajuda e às vezes eles não têm conhecimento... os que fizeram os módulos podem auxiliar" (M05) ${ }^{5}$. "Aqui neste colégio ainda não tive, mas a professora que trabalha lá comigo na outra escola, ela já tem domínio maior, assim, do uso...” (M06).

Pode-se considerar, então, que a participação do professor nos módulos de formação docente contribui para o andamento do processo, situação idealizada por todos os envolvidos com o Projeto de Formação Docente.

Em relação à dinâmica de uso do laboratório, foram resumidas as falas dos sujeitos participantes, para dar a entender como ocorre o processo em cada escola.

5 Em relação à categorização dos sujeitos, todas as falas identificadas como A são dos alunos; D das Direções; $\mathrm{M}$ dos monitores e P dos professores. Ao lado de todas elas foram colocados números - de 01 a 07 que representam as sete escolas visitadas, sendo que todos os sujeitos que possuem ao lado de sua letra o número 01 são da mesma escola, assim como aqueles que possuem os outros números $(02,03,04,05,06$ e 07). Essa classificação buscou facilitar a compreensão em relação a totalidade do pensamento da escola, sendo, por isso, assim mantida.

V. $7 \mathrm{~N}^{\mathrm{o}}$ 3, dezembro, 2009 
Na escola 01 (E01), de acordo com o gestor entrevistado (D01), é a professora titular de cada turma que elabora as aulas no laboratório, comunicando com antecedência a professora que coordena a sala de informática. A professora titular utiliza a informática dentro das disciplinas que ela acha que tem necessidade de trabalhar. O laboratório é utilizado com o intuito de fazer uma aula diferente, ou para pesquisa, consulta, ou mesmo para um conteúdo específico. Ainda em relação ao planejamento, o professor coordenador mencionou que este estava sendo montado e, como na escola as professoras planejam juntas os conteúdos, assim vão fazer também com as aulas de informática.

"Então senta-se, discute-se, prepara a aula, se vê qual é a técnica mais adequada pra dar o conteúdo, até depois que a gente aplica, discutir se deu certo, deu errado, o que tem que ser melhorado, aprimorado, o que não deu certo, o que vamos ter que abrir mão...” (P01).

O gestor (D01) diz que o laboratório estava sendo usado durante três tardes para os alunos da $1^{\mathrm{a}}$ a $3^{\mathrm{a}}$ série. As $4^{\mathrm{a}}$ s séries que são à tarde já haviam conhecido o laboratório, mas nenhum professor tinha agendado para lá trabalhar até então. Pela manhã vai funcionar por agendamento, mas a escolas estava esperando a chegada do monitor/estagiário. De acordo com ele, "usa-se quando tem uma pessoa responsável junto" (D01).

Em relação à preparação para as aulas, o professor coordenador (P01) assim explica seu funcionamento:

\begin{abstract}
"A preparação é do professor titular da turma. Então ele, mais ou menos dentro daquilo que ele está trabalhando [...] vem pra cá e fazer, ou daqui ir pra sala de aula e trabalhar, então isso é com o professor titular [...]. Na verdade o funcionamento é esse, a professora vem junto... Até as primeiras aulas fui eu que conduzi, só que agora eu já disse pra elas: a partir da semana que vem quem vai conduzir é a própria prô; eu vou auxiliar no que for necessário: se os alunos têm dificuldades, se eles não conseguem entrar nos programas, se eles ainda não têm domínio do mouse, quem sabe até ajudar com a mão. Então esse é o meu papel, mas pra coordenar a aula mesmo, é o próprio professor" (P01).
\end{abstract}

$\mathrm{Na}$ escola 02 (E02), o gestor mencionou que os professores utilizam o laboratório com projetos. O professor faz o projeto dele e, dentro de cada projeto, os professores utilizam o laboratório. O professor coordenador confirma essa dinâmica de uso, apontando a forma de utilização:

“[...] Todo professor tem um projetinho, e a gente não deixa o professor vir no laboratório se não tiver um projeto elaborado. Tipo assim: tu utiliza um software do Kelix, qualquer um, só que isso vai relacionar de alguma maneira a tua aula [...]. Eu posso assim, às vezes, dar sugestões. Tu relaciona varias coisas, é interdisciplinar. Então, sempre se faz um projeto, saber o que tu quer com tua aula de informática, o que tu quer que teu aluno aprenda com isso... Então é bem planejado, a gente faz o projetinho todo certo pra poder trabalhar aqui dentro $[\ldots] "(\mathrm{P} 02)$.

O gestor aponta que o funcionamento do laboratório está ocorrendo "nos turnos da manhã e tarde. Sempre tem possibilidade, mesmo quando os professores responsáveis ou o monitor não estejam, quando eles não estão, a coordenação, direção sempre ajuda" (D02). Já em relação à preparação das aulas, os projetos têm que ser feitos da seguinte maneira:

"Tem que ter uma coisa organizada assim [...], não precisa nem me entregar, mas tem que ter
uma coisa organizada no caderno dele, porque trazer os alunos aqui por trazer não vale a pena
$[\ldots .$.$] posso trazer e organizar algumas coisas, mas no laboratório não sou eu que to dando a$
aula e sim to apenas auxiliando [...]" (P02).

Já na escola 03 (E03), o gestor entrevistado apontou que de $1^{\mathrm{a}}$ a $4^{\mathrm{a}}$ série usa-se o laboratório para as questões pedagógicas, auxiliando as matérias de sala de aula. Segundo ele,

"Nesse ano de 2008, o laboratório funciona normal no turno da manhã, pois é o turno em que trabalha a professora responsável. À tarde os professores titulares não têm uma pessoa 
responsável para auxiliá-los no laboratório, portanto, ficou difícil utilizá-lo porque eles não fizeram a formação nos módulos do projeto oferecido pela UPF e PMPF e a escola ainda não realizou o processo de multiplicadores do projeto, como idealizado. A professora responsável atende os alunos do turno da manhã, sendo que os alunos do turno da tarde por enquanto não estavam tendo aula no laboratório, até que chegasse o novo estagiário" (D03).

Ainda em relação ao planejamento de uso, o professor responsável mencionou o seguinte:

\begin{abstract}
"Os alunos de $1^{\mathrm{a}}$ a $4^{\mathrm{a}}$ série têm horário fixo. De quinta a oitava série eles vêm de acordo com a solicitação dos professores. Nos horários livres [...] eles agendam um horário e podem vir pro laboratório pra fazer trabalhos de pesquisa e também trabalhos... não só de pesquisa em internet, mas de manuseio mesmo, de digitação, de parte de desenho, das ferramentas do computador [...]. Mas por enquanto quem tá tendo acesso são as turmas da tarde, as $3^{\mathrm{a}}$ e $4^{\mathrm{a}}$ séries, $7^{\mathrm{a}}$ e $8^{\mathrm{a}}$. E a tarde, $1^{\circ}$ ano, $1^{\mathrm{a}}$ série e $2^{\circ}$ ano estão vindo ao laboratório também, porque tem um monitor que vem uma tarde por semana pra atender o currículo com horário fixo" (P03).
\end{abstract}

O gestor aponta que o laboratório funciona "de manhã com a professora responsável e de noite com a parceria entre o aluno da Ciência da Computação com a SME. A tarde ainda não está funcionando por falta de estagiário" (D03). Em relação à preparação das aulas, o depoimento do professor coordenador foi o seguinte:

\begin{abstract}
“No início aconteceu de 'ah, vamos ir lá pro laboratório', daí eu digo, tá, mas vamos fazer o que lá no laboratório? Então bem no início a gente trazia, a gente dispunha alguns jogos pra eles e deixava pra reconhecimento de teclado, pra uso do mouse, pra nomenclatura das partes [...], então no início a gente tava reconhecendo, eu propus as coisas pra eles [...] mas hoje já não acontece isso, hoje não tem mais" (P03).
\end{abstract}

Acredita-se que essa exploração inicial dos computadores é necessária, mas essa utilização do laboratório sem ter uma finalidade, a qual diz o professor que "hoje não tem mais" não pode ser recorrente, porque a informática tem várias características que podem ser utilizadas de forma a potencializar processos de aprendizagem e várias habilidades dos alunos.

$\mathrm{Na}$ escola 04 (E04), em relação à política de uso, o gestor mencionou que a prioridade é para os alunos, pelo fato de haver somente uma professora para atender:

\footnotetext{
"No turno da manhã o laboratório não está funcionando porque não têm uma pessoa responsável que assuma isso. Em janeiro de 2008 foram desligados os monitores, tendo a proposta que a partir de abril os monitores voltem à escola. De tarde a coordenadora estabeleceu um horário para atender 8 turmas (50 min cada turma), divididos na segunda, terça e quarta-feira, sendo que na quinta-feira a escola vai sediar a continuação do curso oferecido pela Prefeitura, e na sexta não terá funcionamento, pois a professora responsável não se encontra" (D04).
}

O gestor explica que o laboratório só funciona quando há a presença de uma pessoa responsável junto. Quando a pessoa responsável pelo laboratório não se encontra, algumas professoras levam os alunos por conta, mas isso pouco acontece. Já em relação à preparação das aulas, o professor coordenador (P04) menciona que sempre combina as atividades com a professora titular da turma antes da aula, pois, daí, quando as crianças chegam, os computadores já estão preparados, com o programa ou site aberto e prontos para serem usados. Ele salienta que todas as atividades possuem cunho educativo, sejam os jogos ou os sites.

$\mathrm{Na}$ escola 05 (E05) o gestor (D05) confessou que para o planejamento do uso do laboratório a escola teve bastante dificuldade nesse ano:

\footnotetext{
"No ano passado, quando foi implantado, teve o pessoal todo qualificado, os professores fizeram curso em férias, depois esse ano, quando retornou, teve uma mudança no quadro de professores, tiraram os professores que tinham solicitado todo esse planejamento, então foi
} 
enxugado o quadro e agora que vai reiniciar, praticamente no mês de abril. A professora responsável tem duas tardes e uma manhã, então a escola não tá tendo como era o primeiro ano, atendimento direto: manhã e tarde. Então está falho no sentido que tiraram da escola as pessoas que atendiam... já não tá sendo o que teria que ser, o objetivo inicial, que foi toda a motivação de sempre, agora está com uma falha. Somente essa semana mandaram um monitor para ajudar [...]” (D05).

Já em relação ao planejamento de uso, por haver um monitor na escola, foi perguntado a ele como era o planejamento para o uso do laboratório de informática da escola. Por estar há pouco tempo na função, mencionou o seguinte: "Eu acho que eles trabalham no computador de acordo com o conteúdo que tão dando em aula, daí os professores conversam com a gente pra gente dar de acordo com a matéria" (M05).

O professor coordenador confirmou o que dizia o monitor, mencionando que

"Existe um planejamento sim, com o professor de classe, sobre o que ele está trabalhando. Então, no caso, as séries iniciais, a gente trabalha mais palavras, a ortografia, jogos de lógica [...]. Eu trago bastante produção textual no editor de texto, então geralmente o professor faz planejamento de acordo com o que ele tá trabalhando para o trabalho no laboratório" (P05).

O gestor (D5) afirma que o laboratório está sendo usado quando o professor responsável para atendê-lo está presente, ou seja, nas segundas e nas quintas à tarde, e em algumas manhãs, mas não todas. Menciona ainda que com a chegada do monitor, os horários serão refeitos e à tarde o laboratório será mais usado.

Já em relação aos procedimentos utilizados para a preparação e condução das aulas no laboratório, o monitor coloca que "a gente conversa com os professores e daí a gente prepara joguinhos ou alguma coisa na internet de acordo com o que eles tão vendo em aula" (M05). O professor coordenador ainda diz mais: "A gente tem reuniões nas quartas-feiras, onde a gente elabora e discute o que vai ser trabalhado durante a semana. Todas as quartas a gente se reúne e vê o que tem, o que aconteceu..." (P05).

$\mathrm{Na}$ escola 06 (E06) o gestor fala do planejamento:

“Trabalha-se na parte diversificada, nessa situação de inclusão digital aliando literatura e informática, que é o nome de um dos projetos da parte diversificada da escola. A escola tem a meta de tornar esse, se apropriando da inclusão digital, já daí com as suas competências de leituras ampliadas. Quanto à distribuição das máquinas, como as turmas não são muito grandes, elas vão uma vez por semana ao laboratório. Somente uma turma de 34 alunos foi dividida em dois horários. Como a escola tem o projeto Literatura e Informática, já estão assegurados dois períodos para cada turma de $5^{\mathrm{a}}$ a $8^{\mathrm{a}}$, e séries iniciais é uma hora por semana, além do projeto de turno integral [as crianças ficam até as $18 \mathrm{~h}$ na escola] que eles têm possibilidade de ficar mais uma hora na informática e na escola" (D06).

O professor responsável pelo laboratório fala sobre o planejamento de uso:

"Eu sempre converso com as professoras, eu venho três manhãs e uma tarde. Ainda esse ano nós não nos planejamos [...] mas o planejamento nosso é trabalhar em cima de projetos, onde os professores planejam suas aulas e 'em que momento está incluída a internet e o laboratório'? Durante o andamento... [...] Agora de imediato, como é o começo do ano e como tivemos muita coisa ainda não deu pra se programar assim, mas a intenção de trabalhar é essa, vai ser essa ao longo do ano, de nós elaborarmos projetinhos e 'aonde que eu posso usar o laboratório'? 'Qual é o tema que eu vou desenvolver'?. [...] mas nunca eles vêm aqui, 'ah, não tem o que fazer', é um depósito de alunos... não, isso posso te garantir que não acontece..." (P06).

O monitor também fala sobre como vem sendo utilizado o laboratório: "Tá todo dividido, cada professora tem um horário e tem, tipo, uma atividade pra cada série, cada turma” (M06). O gestor fala então sobre quando o laboratório é usado: 
"É usado no horário normal de aula, sendo que eventualmente é aberto para os alunos do turno inverso, para pesquisa. A professora responsável vem duas manhãs e duas tardes e o estagiário do Propet vem de $3^{\mathrm{a}}$ a $6^{\mathrm{a}}$-feira, de tarde, mas usa-se o laboratório também em outros momentos, já que a escola tem o projeto de literatura e informática e outras professoras trabalham também no laboratório" (D06).

Em relação aos procedimentos que são utilizados para a preparação e condução das aulas no laboratório, o monitor menciona que "geralmente a professora que vem pra mim ou pra professora da informática pedir se tem possibilidade de usar tal jogo, se pode... se tem algum jogo pra aquela matéria, tipo matemática, essas coisas" (M06). Já o professor responsável, sobre o funcionamento das turmas e preparação das aulas, mencionou que, "sempre tem diálogo das professoras titulares comigo, ou planejamento por projetos. Mas a aula quem planeja é a professora, e daí eu só auxilio em acessar a internet, abrir os programas, porque tem que ser tudo pronto e tudo ligado, eu deixo tudo pronto". Continua: "A gente dá prioridade assim que todos venham. É uma aula por semana em cada turminha. Os da tarde, que é Ensino Fundamental, de $1^{\mathrm{a}}$ a $4^{\mathrm{a}}$, daí todos eles vêm uma hora, mais ou menos esse tempo, dependendo a necessidade" (P06).

O professor afirma que quando as crianças querem ir pro laboratório, eles querem

“jogar, mas nós não vamos lá pra jogar, porque eles querem aqueles joguinhos lá que não acrescentam nada... [...]. E vai surgindo, a gente tem muito o que aprender, como é que eu vou dizer, é uma coisa bastante nova, estamos caminhando, começando, não sei, de repente não estamos no caminho certo também, tem tudo isso... mas sempre acho que dá pra fazer um monte de coisas lindas, que é importante sim o laboratório" (P06).

Por fim, na sétima escola (E07), o gestor coloca que o planejamento funciona da seguinte forma: "Os professores fizeram o curso e eles atendem os alunos e a comunidade [...]. O laboratório tem um cronograma, eles agendam por turma e quando não é usado por alunos a gente tem tempo pra comunidade" (D07). O professor coordenador, em relação ao planejamento de uso, declara: "Nós trabalhamos através de agendamento. O professor vem, ele tem acesso à agenda, ele escolhe o dia, escolhe o turno, escolhe o momento que ele necessita usar a informática pra ajudar no desenvolvimento da sua aula" (P07).

O gestor menciona que o laboratório é usado, então, todos os dias de segunda a sábado. No turno da tarde, com a professora responsável e de manhã, com o monitor. Quando não tem professor responsável, não é aberto. Já em relação à preparação para as aulas, o professor coordenador relata como se procede:

\footnotetext{
"O professor, antecipadamente, ele deve né, muitas vezes não acontece, colocar na agenda a disciplina que ele vai trabalhar e o conteúdo. Eu venho, olho e já preparo a maquina, já deixo mais ou menos organizado. Quando é aluno maior ele já pode entrar diretamente na internet e ele mesmo pesquisar e a gente fica orientando. Mas se é aluno pequeno, eu já deixo pronto, por ex, vamos trabalhar com figuras geométricas, eu já deixo o Tangran pronto, vamos trabalhar com o alfabeto, eu já deixo o jogo do alfabeto pronto, dependendo o que o professor for trabalhar, ele já entra com a máquina pronta” (D07).
}

Diante disso, percebe-se, no geral, que em quatro escolas existe certa ociosidade na utilização do laboratório de informática, decorrente de falta de monitores para atender toda a demanda da escola. Das sete escolas visitadas, em cinco os horários de cada turma no laboratório são fixos, sendo que as crianças vão ao laboratório semanalmente. Nas outras duas, os horários funcionam por agendamento.

Acredita-se que o planejamento do uso através de horário fixo aos laboratórios, adotado por cinco escolas, é adequado aos objetivos da informática educativa. Tendo em vista que, para muitas crianças o uso de computadores só acontece na escola, ao ser estabelecida 
uma visita semanal ao laboratório, a essas crianças é garantido ao menos esse contato. Em relação ao uso facultativo, que funciona através de agendamento, acredita-se que os mais prejudicados são os alunos, que ficam a mercê da vontade dos professores em levá-los, fato que muitas vezes não ocorre, seja pelo receio dos professores em utilizar a máquina, seja pela inabilidade em relação ao manuseio, seja por comodidade ou outros fatores que, como se sabe, se encontram de forma obstaculizada entre a informática e os professores.

\section{Estimativa quantitativa da freqüência dos alunos no laboratório}

Em relação à estimativa quantitativa da frequiência dos alunos no laboratório de informática, é preciso pontuar algumas percepções. Ao todo, as 07 escolas visitadas atendiam um montante de mais de três mil e oitenta (3.080) alunos.

Apenas em uma escola visitada o professor mencionou que todas as turmas iam ao laboratório semanalmente, perfazendo um total de cerca de 160 alunos. Nas outras seis escolas, compareciam ao laboratório semanalmente cerca de $50 \%$ dos alunos, na seguinte sistemática: uma, com total de 460 alunos, em que cerca de 200 utilizam o laboratório; a segunda, que possui atende de 450 alunos, utilizavam uma média de 130 alunos por semana; na terceira, de um total de 390 alunos, cerca de 200 utilizam o laboratório semanalmente; na quarta, com cerca de 460 alunos, também estavam usando o laboratório somente as séries iniciais, aproximadamente 200 alunos; na quinta, com cerca de 330 alunos, o professor responsável mencionou que uma média de 240 alunos utilizavam a informática semanalmente. Vê-se que, de um universo de 2070 alunos dessas cinco escolas, cerca de 960 utilizavam o laboratório, ou seja, 1110 alunos não tinham acesso aos laboratórios pelo mesmo motivo: falta de monitor, fato que interrompeu a continuidade de uso dos laboratórios, utilizados nessas escolas somente em um turno ou em dias alternados.

Por fim, na sexta escola, que tem mais de 800 alunos, cerca de 200 crianças - que não eram sempre as mesmas - utilizavam o laboratório por semana, pois o sistema é por agendamento e os professores utilizam quando necessitam. Constata-se, com isso, que cerca de 600 alunos não utilizavam o laboratório, ou seja, 70,5\% dos alunos não tinham contato com o laboratório semanalmente.

Essas questões precisam ser consideradas em função do processo de formação dos professores, um amplo investimento em relação aos recursos, aos provimentos tecnológicos, e à montagem da estrutura. Entretanto, por falta de pessoal - por mais que seja por motivos e medidas administrativas que não competem às escolas - a estrutura deixa de atender a demanda para a qual foi preparada, levando a uma ruptura no processo de inclusão digital e de apropriação diferenciada das tecnologias.

\section{Conclusões parciais}

Na medida em que se reconhece a escola como um espaço legítimo de formação do cidadão e, também, de inclusão digital, torna-se fundamental analisar e refletir o funcionamento dos laboratórios de informática. Acredita-se que esta pesquisa pôde fornecer um indicativo significativo da utilização dos laboratórios de dez escolas da rede pública municipal de Passo Fundo/RS.

Pelo que foi visto em uma perspectiva geral da pesquisa, percebeu-se que ainda existem alguns desafios que podem ser apontados diante do trabalho na informática educativa, 
como o despreparo dos docentes em relação ao manuseio, relacionado puramente à técnica. Essa é uma questão que ainda incomoda os professores, porque ainda não dominam todas as ferramentas, causando assim receio no uso. Esse desafio poderia ser sanado se em todas as escolas estivessem presentes monitores com formação específica para isso, o que facilitaria em muito o trabalho do professor, que ao ser auxiliado nessa questão técnica teria mais tempo e disponibilidade para procurar novas e diferentes atividades didático-pedagógicas para propor a seus alunos, a parte pedagógica. Também parece adequado que as escolas tivessem um programa de formação permanente, o que agregaria melhores condições de trabalho aos docentes.

De todo o processo realizado, sejam as leituras feitas ou as visitas às escolas, acreditase que existem algumas questões urgentes a serem tratadas. Uma delas é a necessidade de um processo constante de formação docente, pois diante da velocidade da informação e do rápido avanço tecnológico, quando se fala em informática diariamente existem novidades, fato que não pode ficar distante da escola. Ainda em relação a isso, demonstra-se importante o fato de que mais de um professor por escola faça o curso de formação docente, para que possa, na falta do outro, suprir a demanda existente, não interrompendo o processo de inclusão digital na escola.

\section{Referências}

Capra, F. (2002). "As conexões ocultas. Ciência para uma vida sustentável”. São Paulo: Editora Pensamento - Cultrix.

Castells, M. (2005). A internet e Sociedade em Rede. In: Moraes, D. (org). "Por uma outra comunicação - Mídia, mundialização cultural e poder". 3 ed. Rio de Janeiro, Record, p.225-231.

Lemos, A. (2003) "Cibercultura. Alguns Pontos para compreender a nossa época". Lemos, André; Cunha, Paulo (orgs). Olhares sobre a Cibercultura. Sulina, Porto Alegre, 2003. http://www.facom.ufba.br/ciberpesquisa/andrelemos/cibercultura.pdf. Maio de 2007. 